\title{
An Adult Case of Acute Lymphoblastic Leukemia with Necrotizing Leukoencephalopathy
}

\author{
Tetsuya TsuKAdA, Norihisa MoritA, Takeshi IKEDA, Naoyuki KATAYAMA, \\ Masakatsu NISHIKAWA, Tohru KOBAYASHI, Katsumi DEGUCHI \\ and Shigeru SHIRAKAWA
}

\begin{abstract}
A 19-year-old man with common acute lymphoblastic leukemia (ALL) developed necrotizing leukoencephalopathy (NL) after extensive chemotherapy and irradiation. Clinicians should exercise care in the treatment of leukemia, since chemotherapy has shown a trend of becoming more intensive, and the survival time of patients with leukemia is being extended.
\end{abstract}

Key words: Necrotizing leukoencephalopathy, Acute lymphoblastic leukemia, Chemotherapy, Radiation, Methotrexate

We treated a case of acute lymphoblastic leukemia (ALL) in which necrotizing leukoencephalopathy developed after chemotherapy consisting of intrathecal injection of methotrexate (MTX) and cytosine arabinoside (Ara-C) and cranial irradiation. This paper reports the clinical course of the affected patient and discusses complications in the treatment of patients with ALL.

\section{CASE REPORT}

A 19-year-old man sought medical treatment at a local hospital because of general fatigue, headache, fever and lymphadenopathy. Routine laboratory examinations revealed pancytopenia with an increase in pathological cells. He was referred to our hospital in mid May, 1982.

On admission, his temperature was $36.9^{\circ} \mathrm{C}$, pulse $81 / \mathrm{min}$, and blood pressure $154 / 60 \mathrm{~mm} / \mathrm{Hg}$. Several enlarged lymph nodes were palpable on the left side of the neck, measuring about $1 \mathrm{~cm}$ in diameter. Hepatosplenomegaly was not evident. In peripheral blood, the leukocyte count was $2500 / \mu$ l, with $18 \%$ pathological cells, which were negative for peroxidase staining; the red blood cell count was
$257 \times 10^{4} / \mu l$, hemoglobin $8.2 \mathrm{~g} / \mathrm{dl}$, hematocrit $25.0 \%$, platelet count $5.5 \times 10^{4} / \mu 1$ (Fig. 1) (Table 1). Observation of an aspirated bone marrow sample revealed a nucleated cell count of $38.1 \times 10^{4} / \mu 1$, and a pathological cell count of $84.0 \%$. The surface markers of bone marrow mononuclear cells were E-rosette(-), $\mathrm{Ia}(+), \mathrm{CD} 19(+), \mathrm{CD} 20(+)$ and $\mathrm{CD} 10(+)$. On the basis of these findings, common acute lymphoblastic leukemia was diagnosed. Biochemical data included an increased lactic acid dehydrogenase (LDH) level and a decrease in triglycerides (TG) (Table 1).

In June 1982 treatment was initiated. The patient was given five cycles of VP therapy, which consisted of vincristine (VCR) $2 \mathrm{mg}$ /body intravenously (IV) on day 1 and prednisolone (PSL) $80 \mathrm{mg} /$ body per os (PO) from days 1 to 7 , followed by intrathecal treatment with methotrexate (MTX) $10 \mathrm{mg} /$ body. He was found to be in complete remission on July 15,1982 and was then given seven cycles of VEPA therapy, consisting of VCR $2.5 \mathrm{mg} /$ body IV on day 1, cyclophosphamide (CPM) $300 \mathrm{mg} /$ body dripintravenously (DIV) from days 1 to 3, PSL 60 $\mathrm{mg}$ /body PO from days 1 to 5 and doxorubicin

From The Second Department of Internal Medicine, Mie University School of Medicine, Tsu Received for publication March 8, 1989; Accepted for publication October 13, 1990 Reprint requests should be addressed to Tetsuya Tsukada, MD, The Second Department of Internal Medicine, Mie University School of Medicine, 174, 2-chome Edobashi, Tsu 514, Japan 


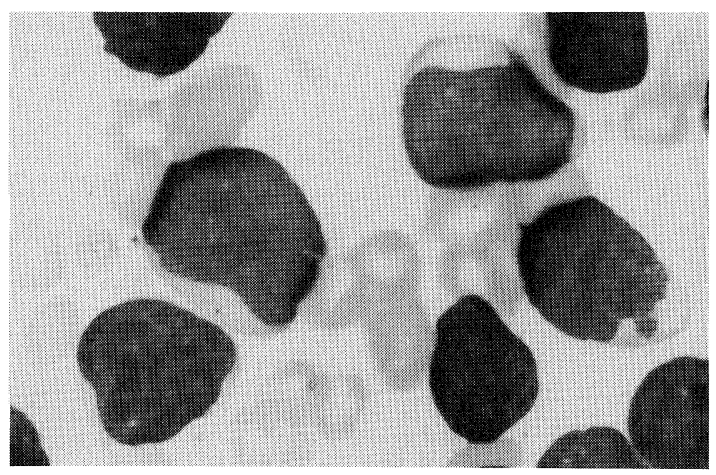

Fig. 1. Morphology of leukemia cells.

(DNR) $30 \mathrm{mg} /$ body IV on day 1 (Aug. 19, 1982). Finally, three cycles of VEMP therapy were given consisting of VCR $2 \mathrm{mg} /$ day IV on day 1, CPM $1000 \mathrm{mg} /$ day DIV on day 1, 6-mercaptopurine (6-MP) $120 \mathrm{mg} /$ body PO from days 1 to 7 and PSL $70 \mathrm{mg}$ /body PO from days 1 to 7 (Fig. 2). He remained in complete remission for two years after the VP therapy. Leukemia recurred in the bone marrow in June 1984 and was treated by mitoxantrone (MIT)-VP therapy, consisting of MIT 12 $\mathrm{mg} /$ body DIV on days 1 and 2, VCR $2 \mathrm{mg} /$ body IV on day 1 and PSL $60 \mathrm{mg} /$ body PO from days 1 to 7 , and MIT-VEMP therapy, which consisted of MIT $8 \mathrm{mg} /$ body DIV on days 1 and 2, VCR 2 $\mathrm{mg} /$ body IV on day 1 , CPM $800 \mathrm{mg} /$ body DIV at day 1 , MTX $50 \mathrm{mg} /$ body DIV on day 1 and PSL $60 \mathrm{mg}$ /body PO from days 1 to 7 . He had achieved a second complete remission by Aug. 28, 1984. After complete remission for eight months under maintenance therapy consisting of MTX 15 $\mathrm{mg} /$ body DIV on day 1 and 6-MP $100 \mathrm{mg} /$ body PO from days 1 to 7 , the patient complained of difficulty in walking and was found to have leukemia in the CNS confirmed by lumbar puncture on Feb. 20, 1985. It was treated with two cycles of intrathecal administration of MTX $15 \mathrm{mg} /$ body, cytosine arabinoside (Ara-C) $20 \mathrm{mg} /$ body, PSL $15 \mathrm{mg} /$ body, two cycles of high-dose MTX 5000 and 7000 $\mathrm{mg}$ /body DIV, and cranial irradiation (cranial lateral parallel opposing portal technique, total 2000 rad). Complete remission had been achieved on Mar. 12, 1985, when the CT scan showed no abnormal findings (Fig. 4-A). Thereafter CNS leukemia relapsed twice during maintenance therapy and was
Table 1. Laboratory findings on admission.

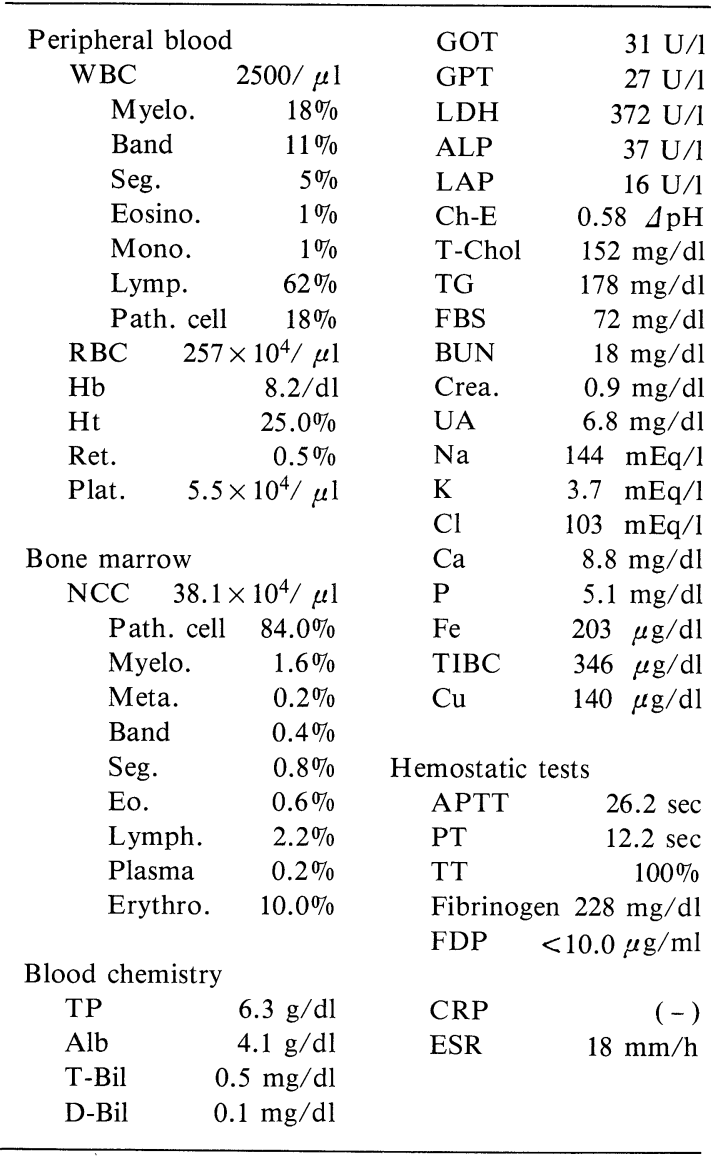

treated by a total of fourteen cycles of intrathecal administration of MTX, Ara-C and PSL (Fig. 2) and craniospinal irradiation (cranial lateral parallel opposing portal technique in head, total $2000 \mathrm{rad}$ ) from Jan. 22 to Feb. 5, 1987 (Fig. 3), resulting in clinical improvement. After a short-term episode of headache and somnolence from Feb. 9 to Feb. 17, 21 days after irradiation (Feb. 26), the patient experienced headache, a decreased level of consciousness (stupor or semicoma) and incontinence. Transient epileptic seizures occurred on Mar. 8 (Fig. 3). His pupils were equal in size, regular, round and responded normally to light. The examination of deep tendon reflexes showed weak responses without focal neurologic signs. Nuchal stiffness and Babinski's sign were not observed. The findings of a lumbar puncture were within almost normal limits 


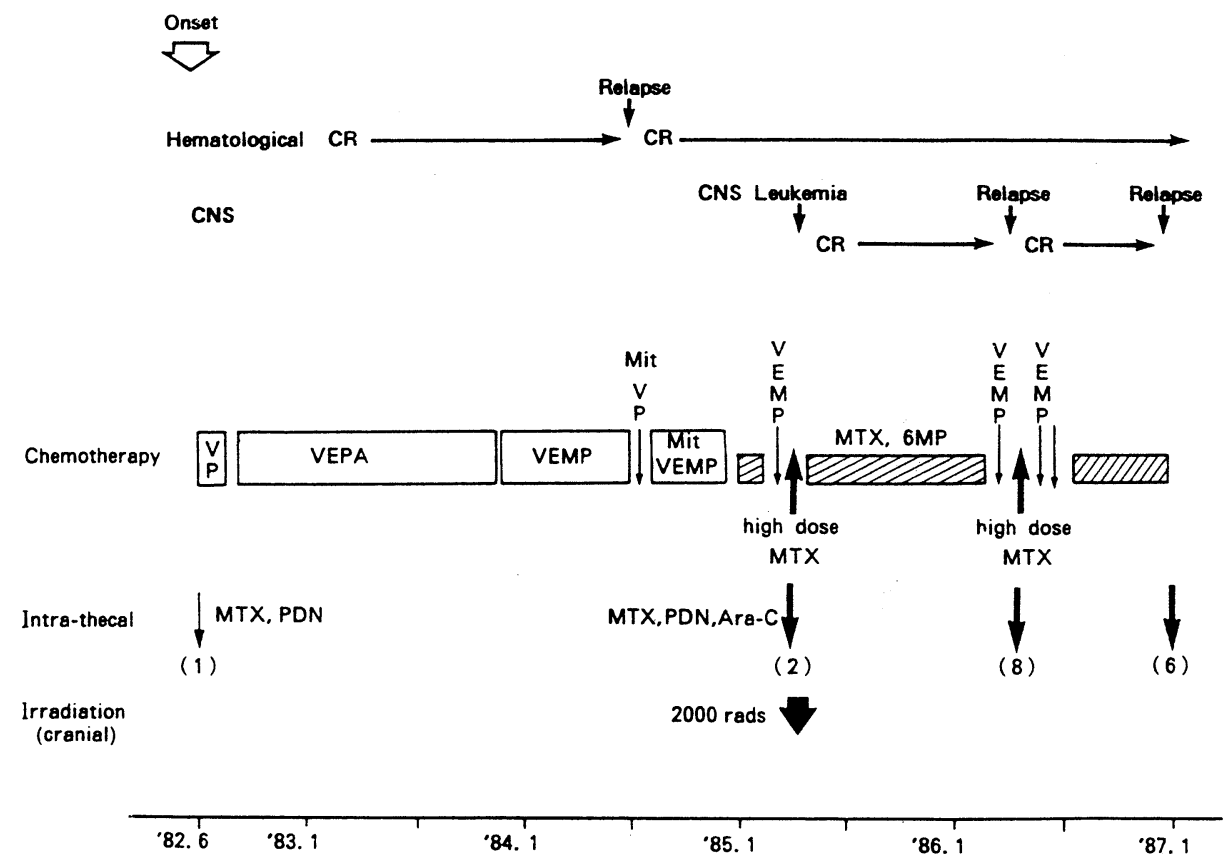

Fig. 2. Clinical course I, Treatments for leukemia.
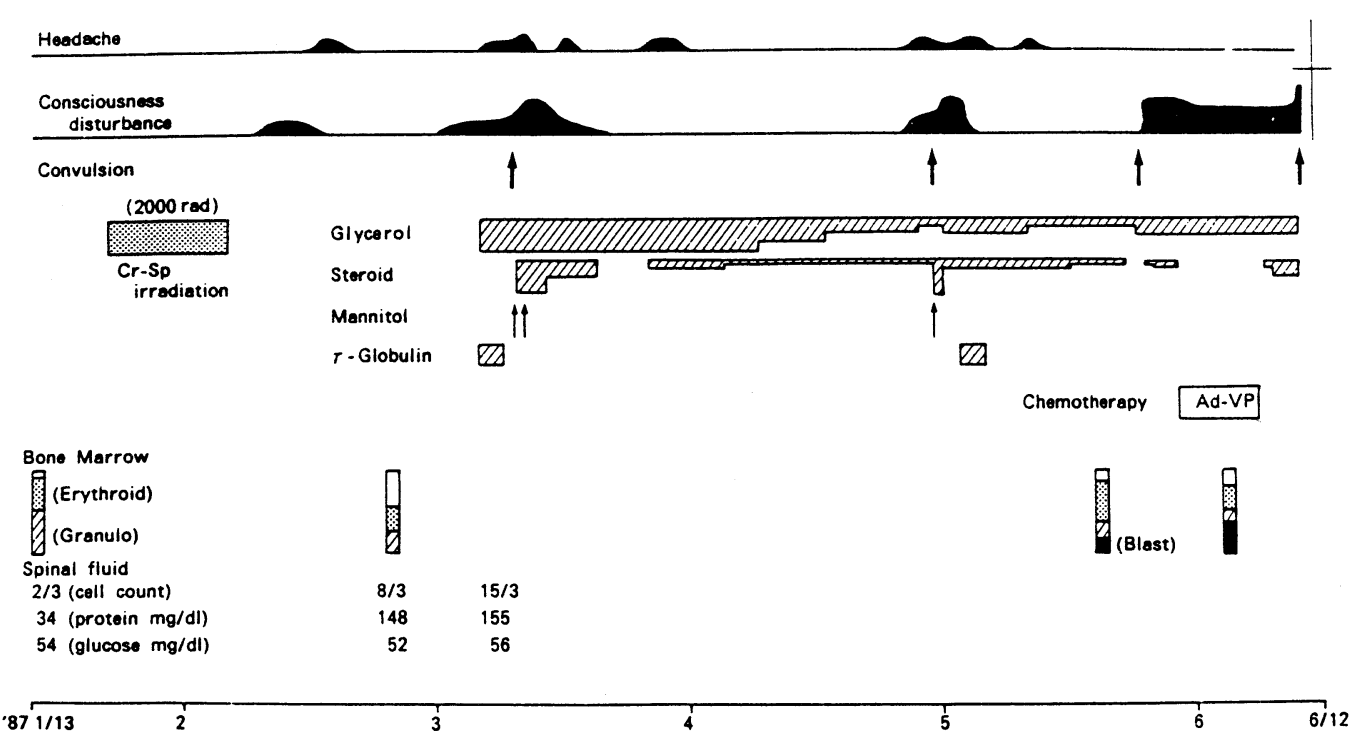

Fig. 3. Clinical course II, Symptoms and treatments in relation to the central nervous system.

with slightly increased protein. Brain CT scans showed edema-like changes in the white matter of both frontal lobes on Mar. 3 (Fig. 4-B). Steroid hormones, mannitol and glycerol were administered, producing transient improvement in consciousness. The CNS symptoms, including a decreased level of consciousness, incontinence and seizures, neither improved nor worsened. On April 16, 1987, brain CT 


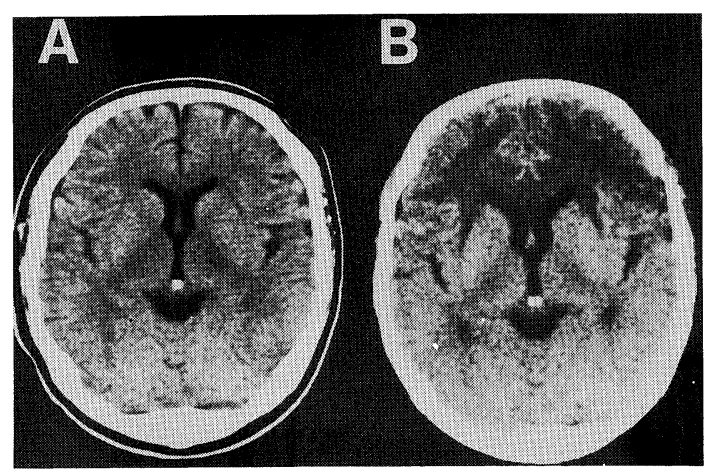

Fig. 4. Findings of $\mathrm{CT}$ scans, $\mathrm{A}$ on first relapse in the central nervous system in Mar 1985, B on first convulsion after second irradiation in Mar 1987.

scans showed no remarkable change in comparison with those of Mar. 3, 1987. Four months later, the patient died due to a relapse of the leukemia.

\section{DISCUSSION}

CNS disturbances in patients with leukemia has been observed in CNS leukemia, progressive multifocal leukoencephalopathy (PML) and the complications of treatment, including necrotizing leukoencephalopathy (NL), somnolence syndrome, chemical arachnoiditis, mineralizing microangiopathy, and so on. In the present patient, the cause of the neurological symptoms did not seem to be due to CNS leukemia because the cerebrospinal fluid was clear and contained hardly any abnormal cells; also, the episode happened immediately after cerebrospinal irradiation. The lack of progressive neurological symptoms and almost constant findings on CT scans were not in accord with PML, somnolence syndrome, chemical arachnoiditis or mineralizing microangiopathy $(2,3)$. Therefore NL was diagnosed in this patient on the basis of the constant clinical features, CT characteristics and the history of heavy treatment with intrathecal and intravenous MTX and cranial irradiation of more than $2000 \mathrm{rad}$, a combination therapy that frequently causes NL (3).

The etiology of NL is commonly multifactorial, but includes radiation, MTX treatment by the intrathecal or intravenous route, and other causes (4). The pathogenesis is well known to be alteration of the blood-brain barrier (BBB) due to irradiation, and vascular disturbance caused by MTX. The change in the BBB due to irradiation induces diffusion of circulating MTX into CNS tissues, and MTX is known to interfere with the metabolism of myelinsupporting elements $(5,6)$. MTX also causes direct causes endothelial damage $(9,10)$. Brant-Zawadzki et al reported radiation-induced occlusive vasculopathy of large intracranial vessels (9). In the present patient, the low-density area seen in CT scans was mainly localized in the bilateral frontal white matter and the symptoms appeared immediately after the second irradiation. Therefore insufficiency of blood circulation to these areas due to intracranial vessel occlusion may have been related to the pathogenesis of NL.

Fifty-five percent of patients who receive $2400 \mathrm{rad}$ of cranial irradiation, intrathecal MTX and intravenous MTX have been reported to develop NL (3). Others have reported that $47 \%$ of such patients who receive more than 3500 rad of cranial irradiation or more than $150 \mathrm{mg}$ of MTX by the intrathecal route develop NL (6). The incidence of leukoencephalopathy after radiation therapy alone, intrathecal MTX alone or intravenous MTX alone is much lower, ranging between $0.5 \%$ and $2 \%$ of children at risk (4). This patient was in critical condition due to $\mathrm{NL}$ at the time of the second irradiation and the radiation dose had to be limited to 1800 rad because one study had indicated notable differences in outcome between groups of patients treated with 2400 vs $1800 \mathrm{rad}$ (10). Clinicians should exercise care when examining patients with leukemia by CT or magnetic resonance imaging (MRI) because there is no known effective treatment for NL and major efforts should be directed at prevention and early detection of this condition. MRI detects the extent of NL more sensitively than CT scan $(10,12)$. The $\mathrm{NL}$ in this patient was thought to have been in the advanced stage from the CT scan findings, since the early-stage disease appears as an extensive periventricular hypodense area (13). Clinicians should thus be more careful when treating leukemia, especially acute lymphoblastic leukemia, because more intensive chemotherapy is often required, the remission period is becoming longer, and the incidence of CNS leukemia has been increasing (14).

\section{REFERENCES}

1) Lauren BK, Richard BL, Michael LS, et al. Progressive 
multifocal leukoencephalopathy; Clinical and radiographic features. Ann Neurol 17: 344, 1985.

2) Berg RA, Ch'ien LT, Lancaster W, et al. Neuropsychological sequelae of postradiation somnolence syndrome. JDBP 4: 103, 1983.

3) Mauer AM, Simone JV. The current status of the treatment of childhood acute lymphoblastic leukemia. Cancer Treat Rev 3: 17, 1976.

4) Bleyer WA, Griffin TW. White matter necrosis, microangiopathy, and intellectual abilities in survivors of childhood leukemia, association with central nervous system irradiation and methotrexate therapy in radiation damage to the nervous system. Gilbert HA, Kagan AR, Eds. Raben, New York, p.155, 1980.

5) Price RA, Jamieson PA. The central nervous system in childhood leukemia. 2. Subacute leukoencephalopathy. Cancer 35: 306, 1975.

6) Rubinstein LJ, Herman MM, Long TF, et al. Disseminated necrotizing leukoencephalopathy; a complication of treated central nervous system leukemia and lymphoma. Cancer 35: 291, 1975.

7) Mei Liu H, Maurer HS, Vongsvivut S, et al. Methotrexate encephalopathy. Hum Pathol 9: 635, 1978.

8) Suzuki K, Takemura T, Okeda R, et al. Vascular changes of methotrexate-related disseminated necro- tizing leukoencephalopathy. Acta Neuropathol (Berl) 65: $145,1984$.

9) Brant-Zawadzki M, Anderson M, DeArmond SJ, et al. Radiation-induced large intracranial vessel occlusive vasculopathy. AJR 134: 51, 1980.

10) Nesbit ME Jr, Sather HN, Robison LL, et al. Presymptomatic central nervous system therapy in previously untreated childhood acute lymphoblastic leukemia: Comparison of $1800 \mathrm{rad}$ and $2400 \mathrm{rad}$. Lancet 1: $461,1981$.

11) Sturceski PJ, Lee PA, Blatt J, et al. Comparable effects of 1800 - and 2400 rad (18- and 24-Gy) cranial irradiation on height and weight in children treated for acute lymphocytic leukemia. Am J Dis Child 141: 550, 1987.

12) Roger JP, Anna TM, Lucy BR, et al. Long-term sequelae of cancer treatment on the central nervous system in childhood. Med Pediatr Oncol 15: 241, 1987.

13) Wendling LR, Bleyer WA, Chiro GD, et al. Transient severe periventricular hypodensity after leukemic prophylaxis with cranial irradiation and intrathecal methotrexate. J Comput Assist Tomogr 2: 502, 1978.

14) Lanzkowsky P. Pediatric hematology-oncology, McGraw-Hill, New York, 1980. 